\title{
A 47-Year-Old Woman With Dysphagia and Food Getting Stuck: What Is Your Impression?
}

\author{
Su Jin Hong, MD \\ Department of Internal Medicine, Soonchunhyang University College of Medicine, Bucheon, Korea
}

A 47-year-old woman presented with dysphagia and food getting stuck for 6 months. There were no abnormal findings on esophagogastroduodenoscopy. She underwent a high-resolution manometry (HRM, version 2.0.1, Manoscan, Sierra Scientific
Instruments, Los Angeles, CA, USA) with a $4.2 \mathrm{~mm}$ HRM catheter equipped with 36 pressure transducers spaced $1 \mathrm{~cm}$ apart. Ten swallows of $5 \mathrm{~mL}$ water was given to the patient in a supine position. Among the 10 swallows, 3 swallows revealed rap-
A

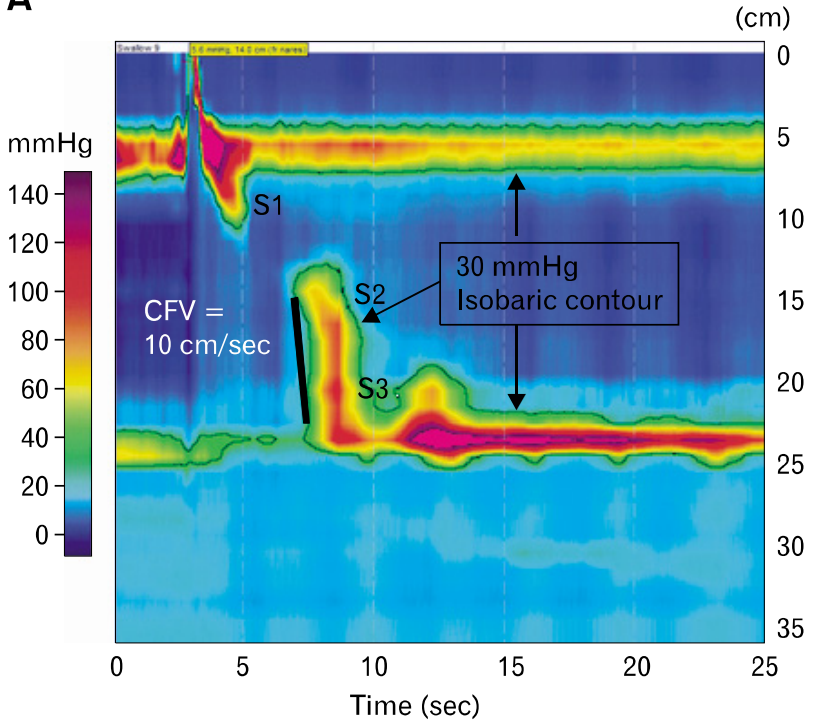

B

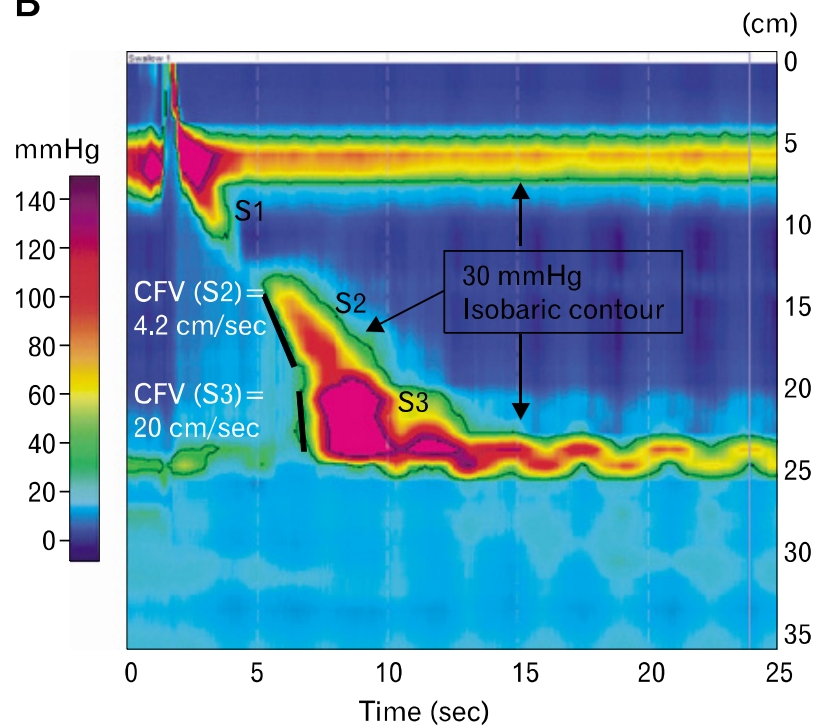

Figure 1. High-resolution manometry findings. (A) It illustrates a swallow with rapid contractile front velocity (CFV) attributable to spasm. The $\mathrm{CFV}$ of 30 and $50 \mathrm{mmHg}$ isobaric contours parallel each other, indicating that no compartmentalized esophageal pressurization has occurred. The $\mathrm{CFV}$ value is $10 \mathrm{~cm} / \mathrm{sec}$ with normal esophagogastric junction relaxation. (B) It shows a swallow with normal CFV (4.2 cm/sec) on S2, although rapid $\mathrm{CFV}(20 \mathrm{~cm} / \mathrm{sec})$ is still observed on $\mathrm{S} 3$.

Received: August 28, 2010 Revised: September 3, 2010 Accepted: September 7, 2010

(c) This is an Open Access article distributed under the terms of the Creative Commons Attribution Non-Commercial License (http://creativecommons. org/licenses/by-nc/3.0) which permits unrestricted non-commercial use, distribution, and reproduction in any medium, provided the original work is properly cited.

*Correspondence: Su Jin Hong, MD

Department of Internal Medicine, Soonchunhyang University College of Medicine, 1174 Jung-dong, Wonmi-gu, Bucheon 420-767, Korea

Tel: +82-32-621-5087, Fax: +82-32-621-5080, E-mail: sjhong@schmc.ac.kr

Financial support: None.

Conflicts of interest: None. 
id contractile front velocity (CFV) $(>8 \mathrm{~cm} / \mathrm{sec})$ attributable to spasm on entire distal smooth muscle esophageal segment (S2 and S3) (Fig. 1A). In contrast, 7 swallows showed normal CFV $(<8 \mathrm{~cm} / \mathrm{sec})$ on $\mathrm{S} 2$ and rapid CFV $(>8 \mathrm{~cm} / \mathrm{sec})$ on $\mathrm{S} 3$ (Fig. 1B). What is your impression by the HRM plots?

In the Chicago classification of distal esophageal motility disorders, distal esophageal spasm is defined when spasm (CFV > $8 \mathrm{~cm} / \mathrm{sec}$ ) is detected in $\geq 20 \%$ of swallows in distal esophageal segment. ${ }^{1}$ Distal esophageal segment is consisted of smooth muscle and composed with S2 and S3. When the spasms involve both S2 and S3, we can diagnose diffuse esophageal spasm by the Chicago classification. But, when only 1 segment of distal esophagus is involved by spasms, the diagnosis should be segmental esophageal spasm. Diffuse esophageal spasm is a quite rare disease according to a previous study. ${ }^{2}$ Among 400 patients, only 6 patients (1.5\%) had a CFV $>8 \mathrm{~cm} / \mathrm{sec}$ in $\geq 20 \%$ of swallows and met the criteria for a rapidly propagated contraction. In this case, the HRM plots are consistent with diffuse esophageal spasm.

\section{References}

1. Pandolfino JE, Fox MR, Bredenoord AJ, Kahrilas PJ. High-resolution manometry in clinical practice: utilizing pressure topography to classify oesophageal motility abnormalities. Neurogastroenterol Motil 2009;21:796-806.

2. Pandolfino JE, Ghosh SK, Rice J, Clarke JO, Kwiatek MA, Kahrilas PJ. Classifying esophageal motility by pressure topography characteristics: a study of 400 patients and 75 controls. Am J Gastroenterol 2008;103:27-37. 